\title{
Detectors, devices and electronics for optics
}

\section{Fajer}

V. Fajer, "Detectors, devices and electronics for optics," Proc. SPIE 9665, Tenth International Topical Meeting on Education and Training in Optics and Photonics, 96651K (3 June 2007); doi: 10.1117/12.2207329

SPIE Event: Tenth International Topical Meeting on Education and Training in SPE. Optics and Photonics, 2007, Ottawa, Ontario, Canada 


\title{
Detectors, devices and electronics for optics
}

\author{
V. Fajer. \\ Center of Technological Applications and Nuclear Development. \\ Calle 30 No. 202 e/ 5 ta y 7 ma. Miramar. La Habana. Cuba.
}

\begin{abstract}
Objectives: The present course is devoted to engineers, physicists, and techniques which require basic tools for applying in experiments, measurements and research with optical instruments.

Content: It is composed of the following topics: photodetectors, semiconductor devices, photomultiplier tubes, Faraday modulators, lock in amplifiers and automatic polarimeters. It begins with the definitions, classification and general characteristics of the photodetectors and its selection criteria for specific applications. There is included a section relative to different types of photodiodes and its differential characteristics, the photomultipliers are described showing its validity and application range. The different characteristics of Faraday cells which are widely employed as optical modulators are analyzed. Lock in amplifiers are shown and its applications in experimental arrangements.

Results: a complex optical instrument (an automatic laser polarimeter) is described where can be applied the knowledge obtained from the previous topics. Laboratory optical practices are included optionally.

Conclusion: this course could be given as a postgraduate course for Master in Science or Ph. D depending on the number and content of selected topics. It has been applied as an obligatory subject of the Optical Master in Science curriculum in the Superior Technical Institute (José Antonio Echeverría) of Havana, Cuba.
\end{abstract}

\section{Keywords: detectors, course, optoelectronics}

\section{INTRODUCTION AND CONTENT}

The specificity of photodetectors and the requirements of the optical experiments recommend a special treatment of the electronics devoted to this application which constitutes the principal aim of the present postgraduate course. In the first part are treated the study of the photosensors and the coupling typical electronic circuits. From the whole universe of photosensors the most deeply study is devoted to two types widely employed: photodiodes and photomultipliers. In both cases there are described principally its exploitation characteristics, equivalent circuits, the noise and signals and the coupling with preamplifiers.

From the rest of the photosensors it has been made a selection among the more used at present and a brief description is included. In the majority of the cases the explanation of the physical processes is excluded. Anyway sometimes, it has been necessary to analyze some functional physical aspects necessary for understanding the characteristics of the devices.

Tenth International Topical Meeting on Education and Training in Optics and Photonics, edited by Marc Nantel, Proc. of SPIE Vol. 9665, 96651K · (c) 2007 SPIE, OSA, IEEE, ICO doi: $10.1117 / 12.2207329$ 


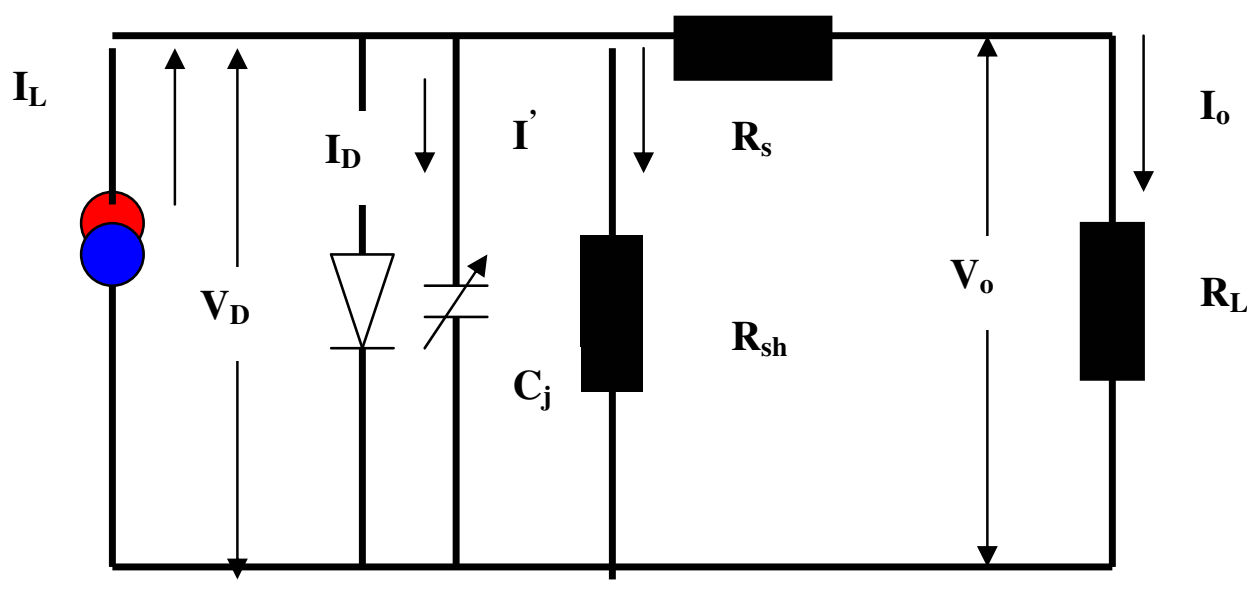

Fig. 1 Equivalent circuit of juncture photodiode (p-n or p-i-n type)

Two conferences are devoted to the study of junction photosensors (Fig. 1) (photodiodes, photocells, phototransistors, etc.) [1], [2] where the photodiodes are studied in more detail. Other 2 conferences are dedicated to the study of photomultipliers [3].

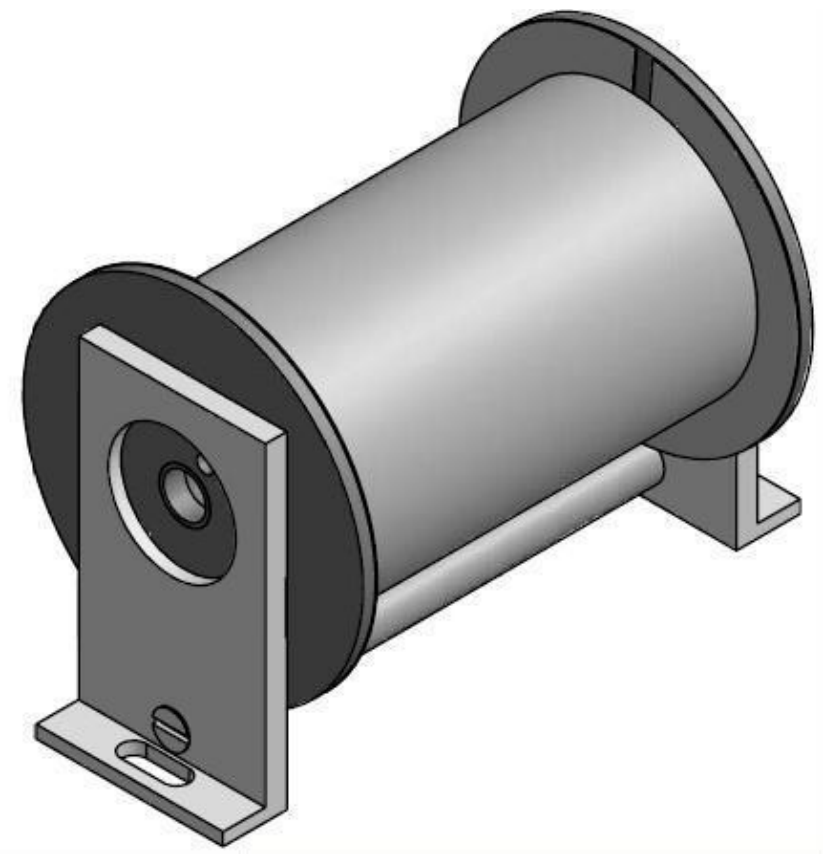

Fig. 2 Faraday cell often employed in optical instruments and experiments.

The modulators are devices commonly employed in experimental setups and optical instruments (Fig. 2) due to the necessity of the analysis of light signals through alternating current signals for its handling by analog and digital electronic circuits, it permits the proper selection of the optimal signal frequency for the specific application. 
Among the modulators employed in optics are found the mechanical switches, the electro optical modulators which employ the Kerr effect and the magneto optical modulators like the Faraday cells [4]. Due to its constructive simplicity and its wide application spectra, the course concentrates in this type of modulator that constitutes and important study objective.

The study of lock in amplifiers constitutes and important topic of the course because of its diffused applications in optics, the mentioned study is exposed in two conferences. The lock in amplifier is a specialized voltmeter of alternating current which uses the synchronic demodulation for measuring the intensity or phase, even in severe noise conditions, it is referred to conditions in which the noise approximate $130 \mathrm{db}$, sensitivity at full scales of $10 \mathrm{nV}$ or $0,1 \mathrm{pA}$ are typical. The instrument can be employed in any case which the signal that could be synchronized with or derived from a suitable reference signal. The output of the lock in amplifier, a direct voltage sensitive to phase and proportional to the useful signal, is available for recorders or for future processing. It can also be employed as a control signal for a closed loop system.

For observing the application of the photodetectors and circuits studied in a complex optical instrument (Fig. 3) it was selected an automatic laser polarimeter for this purpose [5],[6]. The polarimeters are instruments which measure the rotation of the light polarization plane after traversing an optical active substance. This fact permits that these instruments determine the concentration of substances like glucose, essential oils and hundreds of raw materials and pharmaceutical products being of great utility in the sugar and pharmaceutical industries, in clinical laboratories and other branches of the chemical and biochemical analysis.

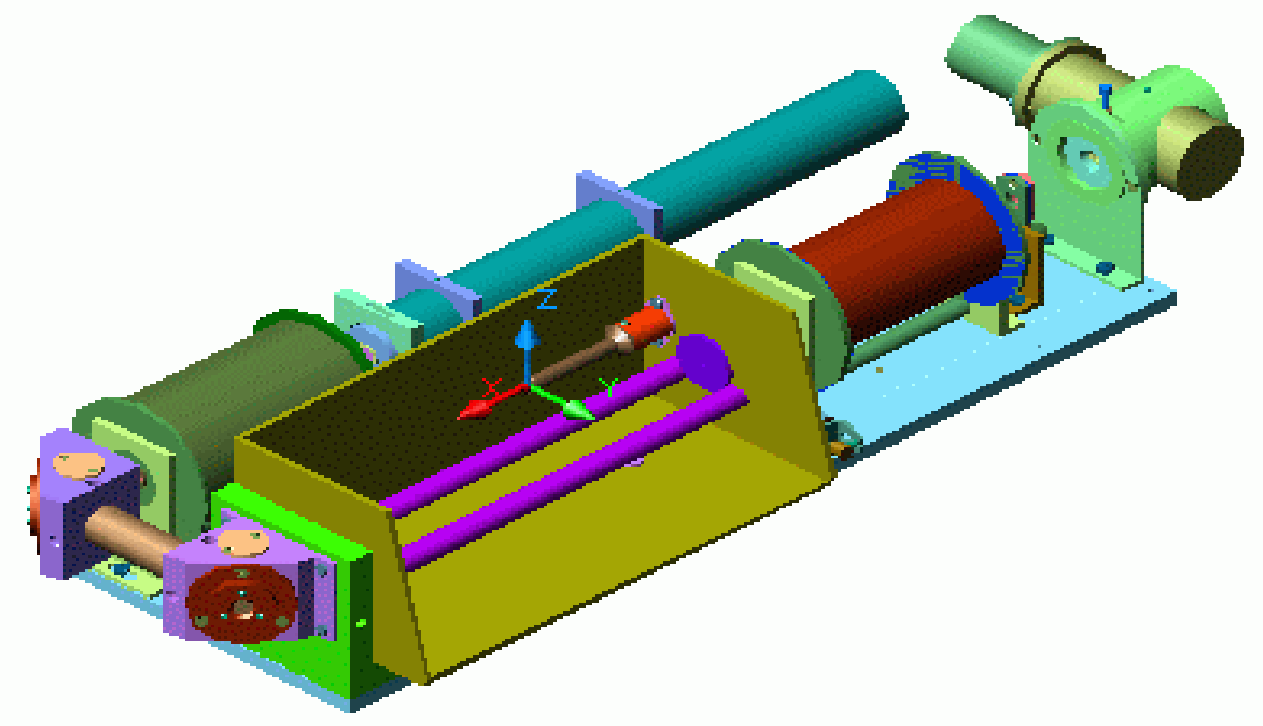

Fig. 3 Optical bench of the automatic polarimeter LASERPOL that includes a photmultiplier as optical detector and Faraday cells as modulator and compensator.

In two conferences are presented some of the electronic circuits of the automatic polarimeter LASERPOL 101 developed by the Centre of Technological Applications and Nuclear Development (CEADEN). This instrument has the magneto optic system as working principle. 


\section{CONCLUSION}

The referred course accomplishes the necessity of given in a short time a valuable and integrated information for physicists and engineers working in the field of optics and its applications.

\section{REFERENCES}

[1]Boropay, E. P., Torpachev, P.A. (1988):Technica Fotometric Visokogo Amplitudnovo Razresheniya. Universitetskoe. Minsk (in russian).

[2] Melles Griot -Photonics Components (2005). Catalog, 160.

[3] Hamamatsu, (2006), Photomultipliers tubes, Catalog, 90.

[4] Fernández H., (2004): Mechanical documentation. Polarimeters LASERPOL.

[5]Fajer, V., (1996): Laser polarimeters: Overview of recent developments, design and applications. Journal of laser applications 8, 43-53.

[6]Fajer V., Duarte N., López J.C., Torres R., Colomé T., Combarro A., Díaz J.L.(1998):Electronic polarimeter. U.K. Patent. GB2286244A 